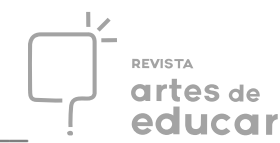

\title{
ALICE EM AULAS DE MATEMÁTICA: O RELATO DE UMA ESTUDANTE COM ARTROGRIPOSE NO ENSINO REGULAR
}

Dilson Ferreira Ribeiro ${ }^{\mathrm{i}}$

\begin{abstract}
Resumo: O texto é a análise do relato de uma estudante da Educação Básica com artrogripose. O objetivo é permitir com que professores compreendam a necessidade de desmistificar ideias que rotulem todos os deficientes físicos como pessoas que tenham dificuldades de aprendizagem. Toma-se como referência, aulas de Matemática em uma Educação Inclusiva cujo destaque é o respeito à singularidade e à diversidade. Nas seções, consideram-se fatores cuja reflexão permite com que professores levem em consideração, ao desenvolver suas propostas de ensino, o fator humano. Assim, a análise conclui que, por mais severa que seja a deficiência de um estudante, há que se levar em consideração suas habilidades, permitindo com que propostas de ensino possam ter êxito, de acordo com as limitações de cada pessoa.
\end{abstract}

Palavras-chave: Artrogripose; Ensino de matemática; Educação inclusiva.

\section{ALICE IN MATHEMATICS: A STUDENT'S REPORT ON ARTROGRIPOSIS IN REGULAR EDUCATION}

\begin{abstract}
The text is the analysis of the report of a student of Basic Education with arthrogryposis. The goal is to enable teachers to understand the need to demystify ideas that label all physically challenged people with learning disabilities. It is taken as reference, Mathematics classes in an Inclusive Education whose highlight is the respect for uniqueness and diversity. The sections consider factors whose reflection allows teachers to take into account, when developing their teaching proposals, the human factor. Thus, the analysis concludes that, however severe a student's disability may be, his or her abilities must be taken into account, allowing teaching proposals to succeed according to each person's limitations.
\end{abstract}

Keywords: Arthrogryposis; Mathematics teaching; Inclusive education.

\section{Introdução}

O presente relato é construído a partir de um questionamento: de que forma um professor pode reconstruir seus conceitos enquanto educador quando em sala de aula temos uma pessoa com severas limitações físicas as quais, em algumas circunstâncias, demonstram um papel de empoderamento capaz de obrigar ao professor rever suas práticas e se adequar a outras propostas de ensino?

\footnotetext{
(c) (i) (2)

2019 Ferreira Ribeiro. Este é um artigo de acesso aberto distribuído sob os termos da Licença Creative Commons Atribuição Não Comercial-Compartilha Igual (CC BY-NC- 4.0), que permite uso, distribuição e reprodução para fins não comercias, com a citação dos autores e da fonte original e sob a mesma licença.
} 


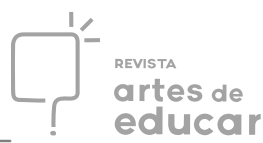

Esse questionamento poderá ser parcial ou totalmente respondido no decorrer deste texto o qual mostra como personagem principal, uma estudante com artrogripose em aulas de Matemática, na Educação Básica.

O objetivo aqui pretendido é permitir com que professores de Matemática ou de qualquer outra área do conhecimento revejam seus conceitos e compreendam que há a necessidade de desmistificar a ideia de que pessoas com limitações severas, como a deficiência física causada pela artrogripose, não necessariamente tenham limitações cognitivas. Em conjunto a essa ideia, oportuniza-se uma leitura que permite uma estudante com deficiência mostrar suas vivências na construção de seus conhecimentos, de tal forma que essa construção seja igual ao ocorrido com os demais estudantes, permitindo dessa maneira com que sejam respeitadas suas limitações, sem desprezar as suas habilidades.

De tudo isso, destaca-se a complexidade em se propor mudanças em concepções muitas vezes construídas como verdades imutáveis, haja vista o fato de que [...] o problema não é mudar a "consciência" das pessoas, ou o que elas têm na cabeça, mas o regime político, econômico, institucional de produção da verdade. (FOUCAULT, 1993, p. 14). Essas considerações vão ao encontro da necessidade de os educadores reverem suas atitudes e compreender que a prática deve ter por objetivo atingir a expectativa de todos, estudantes e educadores, e não apenas de quem às propõe.

A artrogripose é, segundo Oliveira et al. (2018) uma palavra de origem grega que define articulações rígidas. Para os autores, é uma síndrome [...] caracterizada por graves deformidades e contraturas articulares múltiplas, associadas à atrofia muscular. Mesmo com deformidades grosseiras, o paciente se caracteriza por uma excelente adaptação às dificuldades, por apresentar uma inteligência acima da média. (p. 688). Sendo assim, e de acordo com essa definição, a estudante personagem principal desse texto tem como característica o movimento apenas do crânio, os demais membros são rígidos. Para sua locomoção, a estudante aqui nomeada ficticiamente de Alice, utiliza uma cadeira de rodas cujo total controle está em um aparelho adaptado, o qual a mesma consegue comandar com o auxílio de sua língua.

Além disso, Alice consegue, com o auxílio de uma prancheta, escrever segurando o lápis com sua boca. Em seus momentos de lazer, Alice navega em suas redes sociais e tem total interação com o mundo virtual, conseguindo navegar na tela de seu smarthphone por meio da língua a qual faz o papel da ponta de seus dedos. 


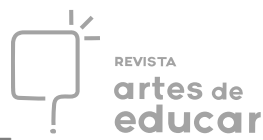

Alice tem como característica a boa conversa. Falando corretamente e de forma expressiva, cativa todos com seu sorriso. Em sala de aula, a única característica que a difere de seus colegas é o fato do enrijecimento de seus membros superiores e inferiores, ademais, Alice consegue interagir com seus colegas, participar das aulas, aprender o conteúdo como qualquer outra pessoa de sua classe e vencer os desafios propostos por seus professores, demonstrando agilidade de raciocínio, capacidade de aprendizagem e dificuldades como qualquer outro.

No entanto, o desafio maior, por vezes, não é somente de Alice, mas de forma equânime, de seus educadores. Além de estar em uma escola que conta com adaptações para que Alice consiga ter um livre acesso a todas as dependências, conta ainda com auxiliares que a acompanham ao transitar de um espaço para o outro, professores auxiliares que se empenham ao estar ao seu lado escrevendo e anotando assuntos que ela julga ser importante em sala de aula, fazendo dessa forma apenas o papel de suas mãos ao escrever. Com isso, Alice acaba desacomodando a estrutura já construída pelo professor e, de forma direta ou indireta, faz com que esses profissionais acabem ressignificando suas práticas e se permitindo mudar quando o tema é trabalhar em uma escola cada vez mais inclusiva. Essas considerações podem ser percebidas no relato de Alice que expressa seu discurso na seção seguinte a esta, relatando o quanto pode ser normal ter uma estudante com artrogripose.

Sobre a escola inclusiva ou ao fato de se propor um ensino inclusivo, não se deve ter como característica apenas o aceitar ou trabalhar com estudantes que tenham alguma deficiência; deve-se, de acordo com Gonzáles Rey (2011) [...] criar espaço subjetivo e social que permita que crianças diferentes se encontrem e sejam capazes de compartilhar as suas atividades. (p. 60). É, dessa forma, uma escola para todos, em uma instituição a qual considera o diferente como diferença pelo fato de o diferente [remeter] ao Um no universo Todo, enquanto a diferença remete a uma operação no Todo [...] (DIAS, 2006, p. 16). Sendo assim, há uma linha tênue ao tratar o outro de forma diferente sem segrega-lo, muito embora tratar essa pessoa sem considerar suas limitações possa contribuir para que a mesma seja estigmatizada num ambiente construído apenas para uma maioria. Assim, há que se compreender a necessidade de avaliar a forma de tratar as pessoas de forma diferente, sem considerar suas diferenças. Ou seja:

Tratar as pessoas diferentemente e, assim fazendo, enfatizar suas diferenças pode muito bem estigmatizá-las (e então barrá-las em matéria de emprego, Revista Interinstitucional Artes de Educar. Rio de Janeiro, V. 5, N.3- pág. 628-641 set-dez de 2019: "Educação: Corpo em movimento." - DOI: 10.12957/riae.2019.45505 


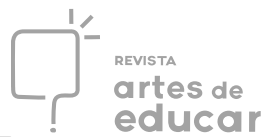

educação, benefícios e outras oportunidades na sociedade), do mesmo modo que tratar de modo igual os diferentes pode nos deixar insensíveis às suas diferenças, e isto uma vez mais termina por estigmatizá-los e, do mesmo modo, barrá-los socialmente num mundo que foi feito apenas a favor de certos grupos e não de outros. (PIERUCCI, 1999, p.106).

$\mathrm{Na}$ categoria de escola inclusiva, a diversidade deve ser considerada como algo favorável ao convívio entre as diferenças. Para Qvortrup (2010) a Diversidade é uma palavra positiva, que combina com outras palavras positivas como democracia, pluralismo, tolerância, respeito pelas diferenças, flexibilidade e assim por diante. (p.1122). Em se tratando da diversidade existente em crianças com deficiência, por exemplo, Qvortrup (2010) afirma que essas crianças têm uma identidade social, uma singularidade a qual permite construir a ideia de que o respeito às diferenças, aos grupos socialmente formados, como étnicos ou de gênero, partem de uma composição única que considere essas pessoas como diferentes, mas em momento algum, elencando essas diferenças como pré-requisito para estabelecer as relações sociais.

No caso da escola, deixar de propor uma metodologia de ensino ou privar esse estudante de experiências as quais são oferecidas para grandes grupos é um ato de exclusão. Do contrário, é desenvolver propostas as quais contribuam com o crescimento de todos, com a construção do processo escolar por todos, respeitando suas singularidades, num entendimento do quanto uma pessoa deva ser reconhecida como sujeito e não destacado por suas limitações. Marchi e Sarmento (2017) vão associar isso às crianças as margens de culturas ideológicas, seja de costumes ou de grupos sociais. Para os autores, as crianças são excluídas para as margens porque [...] escapam ao enquadramento em que se fundam essas bases [...] (MARCHI; SARMENTO, 2017, p. 956).

Em contra partida ao respeito dessa diversidade e singularidade está a capacidade de diagnosticar/ rotular. Em muitos casos, estudantes com deficiência ou laudos são vistos como incapazes, ao invés de, por meio de suas peculiaridades, serem respeitadas suas limitações e, a partir daí, desenvolver suas habilidades que muitas vezes podem ser iguais ou superiores às de pessoas com nenhuma deficiência. Muitas vezes, conforme cita Gonzáles Rey (2011), $O$ defeito não tem um sentido subjetivo em si. [é preciso desenvolver uma] proposta de escola inclusiva [...] essencialmente no resgate da cidadania e no desenvolvimento de espaços sociais que permitam o engajamento dos escolares com defeito em relação de simetria com os seus colegas. (p. 52).

Revista Interinstitucional Artes de Educar. Rio de Janeiro, V. 5, N.3- pág. 628-641 set-dez de 2019: "Educação: Corpo em movimento." - DOI: 10.12957/riae.2019.45505 


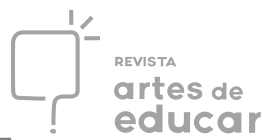

E com essas considerações, enfatiza-se o desejo de uma escola mais inclusiva que respeite a singularidade e diversidade desses estudantes e que trabalhe a diferença apenas como uma característica de todos e não como um empecilho, uma barreira para o desenvolvimento de propostas de ensino ou para a constituição das relações sociais.

Após essas considerações, apresenta-se a estrutura desse texto. Como referência para o desenvolvimento da próxima seção, está a fala de Alice na qual conta suas experiências na Educação Básica, em aulas de Matemática. Alice é uma estudante de uma escola pública no sul do Brasil. Com 17 anos, está no terceiro ano do Ensino Médio e mostra, por meio de sua perspectiva, como é possível oferecer uma metodologia de ensino alternativa para que todos consigam adquirir conhecimento durante suas vivências escolares. A seção intitulada: "O mundo de Alice", foi construída por meio das considerações da estudante em quesitos que tratam de: rotina em sala de aula; hábitos de estudo; instrumentos de avaliações e convívio entre colegas e professores. A seção posterior faz algumas considerações as quais convergem para a resposta do questionamento inicial deste texto, o de compreender de que forma é possível o professor adaptar-se às situações desafiadoras ocorridas em sua sala de aula. As falas de Alice aparecerão em itálico para melhor compreensão do leitor.

\section{O mundo de Alice}

Alice é uma adolescente com algumas peculiaridades. Na escola é querida por todos. Comunicativa e de bom humor, Alice se esforça para seguir as orientações de seus professores como qualquer outra jovem. Fora da escola, relata que fica a maior parte do tempo navegando em suas redes sociais, manipulando seu smartphone conforme descrito na introdução deste texto. Destaca, além das suas habilidades ao escrever com a boca, a forma que utiliza para tomar um simples café, conseguindo segurar a xícara com o maxilar inferior e bebendo normalmente como outra pessoa, segundo seu relato.

Eu só consigo escrever deitada, sentada mesmo apenas dirigir a cadeira porque faço tudo em casa deitada. Quando eu comecei a escrever com a boca minha mãe não queria. Mas aí, fiz uma atividade com papel crepom na escola, na minha primeira série, e eu peguei com a boca, mas eu não tinha noção. Peguei com a boca e cheguei com a boca rosa em casa e minha mãe brigou comigo, porque eu deveria utilizar as mãos, dizendo que tenho mãos 


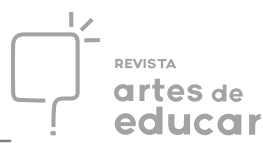

para isso. A partir daí ela começou a perceber que o melhor para mim era a boca. O médico também viu isso e aí comecei a desenvolver essa habilidade. (Alice).

[A estudante d] estaca que antes disso fazia tudo com a mão, mas a partir desse episódio conseguiu perceber que seria mais fácil desenvolver muitas de suas atividades com a boca. Quando cita que fazia tudo com a mão, refere-se ao fato de manipular com dificuldade seus membros superiores, destacando sempre movimentos complexos e que a impediam de segurar qualquer objeto.

$\mathrm{Na}$ sua percepção, no reconhecimento das habilidades de seu corpo, Alice vai ao encontro das palavras de Velásquez (2004) o qual afirma o aprendiz deve ser consciente de que aprender é, em última instância, um ato pessoal que exige esforço e vontade. A motivação é o primeiro passo para isso, mas não é suficiente. (p. 23-24). E esse esforço e essa vontade demonstrada por Alice, ao encontrar a melhor forma de desenvolver suas habilidades diárias, simples para a maioria das pessoas, fez com que ela fosse se adaptando ao fato de que, mesmo com o grau de sua deficiência, conseguisse saber lidar com as limitações de seu corpo.

Assim, com o relato de Alice ao se descobrir ainda criança apta a tomar um café, mesmo sem a mobilidade das mãos, é percebido a confirmação de que os desafios, para qualquer pessoa, devem estar sempre presentes, seja intelectual ou fisicamente.

Para que ocorra o desenvolvimento é necessário que ocorram desafios, ou seja, a criança precisa de experimentação e de motivação para que esse processo seja mantido. É importante que se estimulem os processos de exploração do ambiente, de modo a propiciar novas aquisições e consequente aumento das capacidades físicas e psíquicas. O espaço físico é um elemento indispensável a ser observado e preparado para acolher e instigar a descoberta e a exploração sensorial da criança. (CIASCA, 2015, p.30).

Ao perguntar como seria uma aula de Matemática com Alice, a estudante prontamente responde: normal. Salienta que conversa com seus professores e afirma que consegue escrever com a boca, mas que precisa de uma professora auxiliar para escrever e registar as informações dadas em sala de aula, com mais agilidade. Além disso, destaca o momento de ser avaliada, mostrando a necessidade de precisar de uma prova adaptada para conseguir 


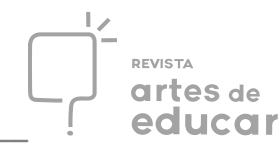

mostrar seu conhecimento adquirido. Após essas considerações, durante essa conversa, percebe-se em sua expressão um semblante de uma jovem que acha muito natural uma aula com estudante cuja mobilidade está apenas na região da cabeça. Alice destaca: eles não pensam que eu sou cadeirante e vão me tratar de forma diferente, não. Eles me tratam da mesma maneira que tratam todos os outros. Eu só não mexo as mãos e não caminho. Percebe-se na fala de Alice o quão normal é para ela ser diferente. Para Beyer (2006), seguindo a perspectiva de Reuchmann, [...] a deficiência deve ser interpretada como uma realidade de indivíduos concretos, inseridos num contexto social, que apresenta suas relações e contradições. (p. 24). O autor ainda compartilha a ideia de que situações de inclusão ocorridas nas escolas criam um rico espaço de aprendizagem para todos, contribuindo para a tolerância e a aceitação de todos, sendo importante para sua vida social e profissional.

Quando destaca a inclusão no ambiente escolar, se adaptava mais na escola pequena em que estudou desde os primeiros anos de sua vida escolar. Ao chegar numa escola bem maior, durante seu ensino médio, sentiu a diferença, mas destacou que isso foi valioso para seu processo de amadurecimento, muito embora afirme que sempre foram respeitadas suas limitações em qualquer instituição de ensino a qual estudou.

Quando o assunto é a relação entre colegas e professores, destaca que sempre teve uma relação tranquila com todos. E com essa afirmação, confirma a ideia de que aprender a conviver e a relacionar-se com pessoas que possuem habilidades e competências diferentes é condição necessária para o desenvolvimento de valores éticos, como a dignidade do ser humano, o respeito ao outro, a igualdade e a solidariedade. (CAMPBELL, 2016, p.140). Nessa reflexão, Campbel (2016) e Beyer (2006) apenas confirmam o quão válido é o convívio com todos e a percepção de que todas as pessoas têm a contribuir umas com as outras, seja por suas capacidades, suas habilidades e até mesmo suas deficiências ou incapacidades, haja vista a ideia de que todos são incapazes em algum campo do saber.

Sobre suas aulas de Matemática, a mais marcante foram as aulas em que o professor exigiu de igual forma para todos e, devido à sua deficiência e a necessidade de ter alguém ao seu lado para copiar do quadro, professores que sentavam junto a ela e explicavam o conteúdo de forma mais atenciosa, são imagens que não lhe saem da cabeça [...] o professor me ajudava, fazia eu responder, já outros não, eles nem perguntavam nada para mim. Perguntavam para todos e meus colegas respondiam, já o professor que eu digo ser meu 


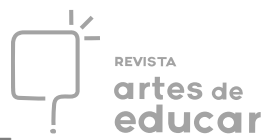

melhor professor me obrigava a participar igual meus colegas. Em meio às afirmações de Alice, percebe-se que uma educação inclusiva deve atender a dificuldade de todos os estudantes, sendo cidadãos respeitados mediante a preservação do direito de aprender.

A educação inclusiva deve ser entendida como uma tentativa de atender às dificuldades de aprendizagem de qualquer aluno no sistema educacional e como um meio de assegurar que os alunos que apresentem alguma deficiência tenham os mesmos direitos que os outros e que todos sejam cidadãos de direito nas escolas regulares, bem-vindos e aceitos, formando parte da vida naquela comunidade. (CAMPBELL, 2016, p.139).

Alice destaca que ser exigida foi sinônimo de se sentir incluída no ambiente escolar. E com isso, percebe-se que o confronto com as diversidades encontradas em sala de aula é um dos principais motivos para se ter uma boa educação. Assim, o professor que transita diariamente entre seus alunos conhece muito bem tal diversidade. Dificilmente aceitaria qualquer premissa de homogeneidade dos seus alunos, pois sabe que são diferentes entre si, assim como não há ser humano igual a outro. (BEYER, 2006, p.27).

Além disso, salienta que em alguns casos já se sentiu mais normal nas aulas em que professores não pedem a participação dela, nem de seus colegas, já que assim, como ninguém participa, ela fica no mesmo nível que os demais de sua turma. Com isso, percebe-se que o que mais marca Alice em uma aula não é um recurso tecnológico ou um instrumento/recurso em que ela tivesse que interagir para aprender algo, mas sim a capacidade de interação entre as pessoas, seja entre ela e seus colegas ou entre ela e seus professores. Sendo assim, o fator humano se faz presente como algo marcante nas aulas dessa jovem com artrogripose. Aulas essas que lhe proporcionaram liberdade. Liberdade de expressão e de experimentação, mesmo estando presa a uma cadeira de rodas. Com isso, Alice mostrou sua liberdade por meio de seu discurso o qual pode ter, em algum momento, desacomodado as concepções de outras pessoas. Para Veiga-Neto (2017), o conhecimento passa a ser entendido como produto de discursos cuja logicidade é construída, cuja axiomatização é sempre problemática porque arbitrária, cuja fundamentação tem de ser buscada fora de si, no advento; discursos que são contingentes e também subjetivos. (p.92). Por essa contingência é que o autor afirma que esses discursos jamais podem ser colocados fora desses acontecimentos e, consequentemente, estabelece-se uma relação de poder a qual a estudante com artrogripose consegue estabelecer regras as quais deverão ser analisadas e, preferencialmente, cumpridas por todos por meio do 


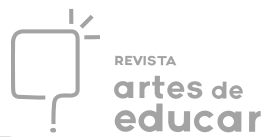

que seu corpo está ditando como necessário para um convívio entre todos. Dessa forma, podemos compartilhar com o autor o chamado práticas discursivas as quais [...] moldam nossas maneiras de constituir o mundo, de compreendê-lo e de falar sobre ele. (VEIGANETO, 2017, p.93). Além disso, Veiga-Neto (2017, p.93) considera que mesmo essa prática estando dependente da vontade de todos, incluindo na nossa, a mesma não é suficiente para gera-la e fazê-la funcionar.

Durante a conversa, quando explana sobre seu aprendizado em aulas de Matemática, destaca que tem dificuldades ou limitações em aprender conteúdos em que sejam exigidas muitas fórmulas ou que contenham cálculos mais densos. No entanto, quando questionada se sua dificuldade é devido à sua deficiência, Alice afirma: Eu acho que uma pessoa, como meus colegas, também tem dificuldades com fórmulas e cálculos. Vejo isso em Física também. Não tem relação com minha deficiência que é mais relacionada com os músculos, não atinge nada de cérebro, meu cérebro é normal assim como o teu. Com isso, compartilha as ideias de Ciasca (2015) as quais abordam a necessidade do estímulo, seja qual for a situação vivenciada pelo estudante, para que consiga obter melhor resultado em relação à aquisição de conhecimento. Nessa perspectiva, Alice afirma que sempre foi instruída por seus professores [a] fazer as atividades propostas, desenvolvendo e estimulando seu raciocínio na mesma proporção que seus colegas, destacando dessa forma sua capacidade em aprender.

Em relação aos processos inovadores em aulas de Matemática para facilitar a compreensão dos estudantes em conteúdos mais densos, Alice afirma que sempre entendia melhor com aula prática. Destaca: Se em Matemática as aulas fossem práticas, eu aprenderia bem melhor. Em outras aulas eu entendo melhor com slides, com mais ilustração do que apenas o quadro e o professor. Eu prefiro mil vezes a aula prática do que teórica. Nas palavras de Alice, uma interação entre conteúdo e situação cotidiana contribui mais no fator aprendizagem, fato este que também é percebido por todos os seus colegas em sala de aula, confirmando que uma aproximação entre realidade e Matemática só tem a contribuir para que esta ciência torne-se cada vez mais acessível a todos os estudantes, com ou sem dificuldades, sempre respeitando suas limitações. Sendo assim, o fenômeno educativo elencado por Mizukami (1986) [...] não é uma realidade acabada que se dá a conhecer de forma única [...] é um fenômeno humano, histórico e multidimensional. Nele estão presentes tanto a dimensão humana quanto a técnica, a cognitiva, a emocional, a sócio-política e cultural (p.1), contribuindo dessa forma com a ideia de que processos inovadores, em algumas situações, são 


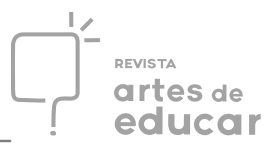

em verdade atitudes diferenciadas, que fogem do trivial quadro e giz, comumente visto em algumas escolas, muito embora seja possível ter uma proposta de ensino inovadora com a utilização apenas de quadro e giz.

Nas avaliações, Alice afirma que fica nervosa. Quando eu vou fazer a prova com a minha professora auxiliar ou com algum professor, eu fico nervosa porque eu penso que a pessoa está com pressa, porque eu vou me enrolar para ler e aí fico nervosa. Nesse quesito, há que considerar-se que o processo de avaliar não deve ser pontual e restrito a questões diretas, ricas apenas em teoria, deixando de lado a interpretação necessária para conectar essa teoria a situações diversas que poderão ser vivenciadas pelo estudante. Para Antunes (2013) [...] 'avaliar' a aprendizagem significa valer-se de uma grande diversidade de atividades que possam colocar o conteúdo que se quer ver aprendido em diferentes contextos particulares. (p.32). Com isso, a realização de um instrumento de avaliação como prova muitas vezes restringe o estudante a um teste de memória apenas. Nessa situação, Alice afirma que não tem a mesma velocidade que seus colegas e, por essa razão, necessita de um tempo extra ou de uma avaliação adaptada à sua mobilidade. Como prefere realizar oralmente, e demonstra capacidade intelectual para isso, Alice sente-se mais à vontade indo para um local reservado do que ficar junto aos seus colegas durante uma avaliação. Além dessas observações, destaca que não vai para a sala de recursos porque não é uma estudante com deficiência no aprendizado.

Quando relata sua experiência em Sala de Recursos na outra escola, de menor infraestrutura que a atual, comenta que fazia as avaliações na Sala de Recursos porque era o indicado para todos os estudantes com deficiência. Alice afirma: [...] lá era assim, todos iam para a Sala de Recursos, era para todos os tipos de doenças: Síndrome de Down, Autismo, cadeirante, tudo. Aqui não.. Percebe-se nessas colocações que Alice, involuntariamente, associa pessoas que frequentam a Sala de Recursos com pessoas doentes, muito embora tenha-se que considerar que pessoas como Alice não são pessoas doentes, mas deficientes. Para a estudante era normal ir para a Sala de Recursos porque todos os estudantes na situação de deficientes acabavam indo e, dentro de sua concepção, isso era considerado normal. Por essa razão, merece destaque o fato de que ter deficiência não está diretamente associado a comprometimento cognitivo. Alice enfatiza que em sua outra escola, estudantes com qualquer deficiência eram encaminhados para a Sala de Recursos, independente de seu comprometimento cognitivo. Isso, de certa maneira, contribui para o equívoco da rotulação 


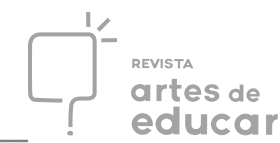

em que uma deficiência física pode ser motivo para a escola não desenvolver um trabalho pedagógico que atenda as habilidades e/ou as capacidades de aprendizagem do estudante deficiente. Surge dessa forma a discussão entre incluir sem excluir.

O rótulo de deficiente cria condições que forjam o desenvolvimento de mentes deficientes. Por mais que a pessoa rotulada se esforce por romper com a realidade relacional instituída, enfrenta toda sorte de resistência e descrédito e é vista como um corpo doente, alguém sem nome, identificada pelo pacote que a contém. (RAAD; TINES, 2011, p. 28).

Quando faz uma avaliação, Alice, ao relatar sua preferência em realizá-la num local reservado, não considera que se sinta excluída do ambiente escolar pelo fato de não fazer junto com seus colegas. Alice também relata que sua prova tem menos questões devido ao tempo entre a leitura da questão e a comunicação com sua professora auxiliar que, segundo Alice, faz apenas o papel de sua mão. Assim, no quesito aprendizado, Alice confirma que consegue aprender como qualquer outra pessoa e que suas incapacidades físicas não são motivos para não atingir seus objetivos como estudante, o de ter uma aprendizagem igual a todos os seus colegas de classe. No entanto, confirma a necessidade de ter instrumentos avaliativos diferenciados bem como a necessidade de o professor auxiliar mas, em hipótese alguma se sente menos preparada que os demais colegas de sua sala para aprender este ou aquele conteúdo.

Na sua perspectiva de uma Matemática mais interativa, Alice compartilha com a ideia de Moysés (2012) o qual, ao afirmar o tipo de relação entre aluno e Matemática, diz esperar [...] vê-la como um saber que o cativa e o instiga a conhecer melhor as situações à sua volta. (p.78), contribuindo assim para que todos os professores compreendam que se o estudante tem ou não limitação física, este tem o direito de ter uma aula a qual o estimule a aprender, seja pela ênfase na relação entre professor e estudante, o que poderia ser chamado de fator humano, seja por atitudes ou técnicas de ensino as quais contribuam para a aprendizagem.

\section{Algumas considerações}




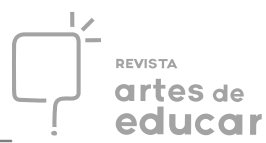

Para destacar algumas considerações em relação ao texto apresentado, a ênfase nesta última seção está em considerar o que é normalidade. Na explanação da fala de Alice, percebe-se que a jovem considera normalidade tudo o que ela vivencia em seu dia a dia, muito embora para uma pessoa que não a conhece, beber café segurando a xícara com o maxilar inferior poderia ser considerado uma anormalidade. Assim, o objetivo deste texto é mostrar que há a necessidade de professores reverem suas concepções quando relacionam deficiência física com limitações de aprendizagem. Como afirma Alice: Eu mesmo não gosto de ser tratada diferente porque estou em uma cadeira de rodas. Nessas considerações, o diferente pode ser considerado, em algumas situações, como aquele que foge à normalidade. $O$ 'diferente' passa a ser visto como sem utilidade econômica. [...] Estar fora, ser diferente, não se submeter às normas homogeneizadoras, é estar excluido ou 'empurrado' para fora. (VERAS, 2014, p. 38).

Com isso, professores que em suas salas de aula possuem estudantes com limitações severas como as ocasionadas pela artrogripose, são profissionais que devem considerar as habilidades desses estudantes, ao invés das suas incapacidades. Alice deixou clara em sua fala que, em muitos casos, uma aula mais atrativa e marcante em sua vida é uma aula repleta de atitudes que priorizem o fator humano, o tratamento igual ao recebido pelos seus colegas e a consideração de seus professores em avaliar suas capacidades ao invés de sua deficiência física. Para Alice, seu desejo é de que "[...] tratem as pessoas iguais a mim como se fossem uma pessoa normal. Ela não pode mexer as mãos e nem caminhar, mas ela é uma pessoa normal. Ela escuta e entende o que estás falando, ela apenas não mexe as mãos e precisa de ti para tudo.”. Em meio a essas considerações há que se avaliar que os professores são, em parte, resistentes a fatores externos aos seus conhecimentos.

Para Nóvoa (2000), Os professores são, paradoxalmente, um corpo profissional que resiste à moda e que é muito sensível a moda. A gestão pessoal deste equilíbrio entre a rigidez e a plasticidade define modos distintos de encarar a profissão docente (p.17). A moda referida pelo autor pode ser traduzida em situações que anteriormente não faziam parte do cotidiano escolar de muitos professores e, com a estruturação de uma escola cada vez mais inclusiva, situações como as vivenciadas por Alice podem contribuir para que esses professores percebam que a deficiência não deve ser considerada como um obstáculo para o ensino e a aprendizagem, mas como um fator adicional que contribui para o aprendizado de todos, seja na criação de uma perspectiva diferente de ensinar estudantes com essa 


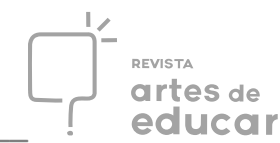

especificidade ou no convívio com o diferente que acaba acontecendo quando o outro, sem deficiência física, acaba vivenciando o dia a dia de um estudante com tais dificuldades como as de Alice.

\section{REFER $\hat{E} N C I A S$}

ANTUNES, Celso. A avaliação da aprendizagem escolar. 10. ed. Petrópolis- RJ: Vozes, 2013.

BEYER, Hugo Otto. Inclusão e Avaliação na escola: de alunos com necessidades educacionais especiais. 2. ed. Porto Alegre: Mediação, 2006.

CAMPBELL, Selma Inês. Múltiplas faces da inclusão. 2. ed. Rio de Janeiro: Wak Editora, 2016.

CIASCA, Sylvia Maria. et. al. Transtornos de aprendizagem: Neurociência e interdisciplinaridade. Ribeirão Preto, SP: Book Toy, 2015.

DIAS, S. Inclusão e Subjetividade: Projeto moral ou ético. Educação e Subjetividade. Ano 1, n. 2, 2006. Disponível em: 〈http://www.gestae.org.br/artigos/inclusao.pdf >. Acesso em: 25 maio. 2019.

FOUCAULT, Michel. Microfísica do Poder. 11. ed. Rio de Janeiro: Graal, 1993.

GONZÁLES REY, Fernando Luis. Os aspectos subjetivos no desenvolvimento de crianças com necessidades especiais: Além dos limites concretos do defeito. In: MARTÍNEZ, Albertina Mitijans, TACCA, Maria Carmen Vilella Rosa (Orgs.) Possibilidades de Aprendizagem: Ações pedagógicas para alunos com deficiência. Campinas, Alinea, 2011, p. 47-70.

MARCHI, Rita de Cássia; SARMENTO, Mamoel Jacinto. Infância, Normalidade e direitos das crianças: transições contemporâneas. Educ. Soc., Campinas, V. 38, n. 141, out. - dez., 2017, p. 951-964.

MIZUKAMI, Maria da Graça Nicoletti. Ensino: As abordagens do Processo. São Paulo: EPU, 1986.

MOYSÉS, Lucia. Aplicações de Vygotsky à Educação matemática. 11. ed. Campinas, SP: Papirus Editora, 2012.

NÓVOA, Antonio. (Org.). Vidas de Professores. 2. ed. Porto Alegre: Porto Editora, 2000. 
OLIVEIRA, Ricardo Kaempf. et al. Osteotomia Intracárpica Biplanar no Tratamento de Pacientes com Artrogripose. Revista Brasileira de Ortopedia e Traumatologia. São Paulo, v. 53, n. 6, fev. 2018, p. $687-695$.

PIERUCCI, Antonio Flávio. Ciladas da diferença. São Paulo: Editora34, 1999.

QVORTRUP, Jens. A tentação da diversidade - e seus riscos. Educ. Soc., Campinas, v. 31, n. 113, out.-dez. 2010, p. 1121-1136.

RAAD, Ingrid Lilian Fuhr; TUNES, Elisabeth. Deficiência como latrogênese. In:

MARTÍNEZ, Albertina Mitijans, TACCA, Maria Carmen Vilella Rosa (Orgs.) Possibilidades de Aprendizagem: Ações pedagógicas para alunos com deficiência. Campinas, Alinea, 2011. p. 15-46.

VEIGA-NETO, Alfredo. Foucault \& a Educação. 3. ed. Belo Horizonte: Autêntica Editora, 2017.

VELÁZQUEZ, Fidela. et al. Matemáticas e Internet. Barcelona: Graó, 2004.

VERAS, Maura Pardini Bicudo. Exclusão Social - Um Problema Brasileiro de 500 Anos:

Notas Preliminares. In: SAWAIA, Bader (Org.). As artimanhas da Exclusão: Análise

Psicossocial e Ética da Desigualdade Social. 14. ed. Petrópolis - RJ: Vozes, 2014. p. 29-52.

\footnotetext{
i Professor de Matemática no Colégio Municipal Pelotense, em Pelotas/RS-Brasil. Mestre em Ensino de Ciências e Matemática pela UFPEL e doutorando do PPG em Educação em Ciências e Matemática da PUCRS, na linha de pesquisa de formação de professores. E-mail: <dilsondfr@gmail.com>, ORCID: <https://orcid.org/0000-0002-0777-9796>.
} 